\title{
Spatial dynamics and consistency of agroclimatic trends in Chile during 1985-2015 to the Köppen- Geiger climate classification
}

\author{
Raul Orrego-Verdugo ${ }^{1 *}$, Rodrigo Abarca-del-Rio ${ }^{2}$, and Claudia Lara-Uribe ${ }^{3}$ \\ 'Instituto de Investigaciones Agropecuarias, INIA Quilamapu, Av. Vicente Méndez 515, Chillán, Chile. \\ *Corresponding author (raul.orrego@inia.cl). \\ ${ }^{2}$ Universidad de Concepción, Facultad de Ciencias Físicas y Matemáticas, Av. Esteban Iturra s/n, Concepción, Chile. \\ ${ }^{3}$ Universidad del BíoBío, Facultad de Ciencias Básicas, Av. Andrés Bello 720, Chillán, Chile.
}

Received: 11 May 2021; Accepted: 12 August 2021; doi:10.4067/S0718-58392021000400618

\begin{abstract}
The Köppen-Geiger classification is one of the most common climate classification systems in the world. It allows classifying ecosystem distribution based on temperature and precipitation, two critical factors in climate, and vegetation cover's sensitivity. We analyzed the dynamics and spatial consistency of agroclimatic variables in each type of KöppenGeiger climate present in Chile, visualizing the variables' behavior throughout the territory. Thus, we computed the trends of different climate and agroclimatic variables in each meteorological station, mapping their slope and statistical significance, and comparing their sense among all those that belong to the same climate zone. Our global trends analysis showed a thermal amplitude decrease in northern and central areas in about $12.03 \%$ and $20.3 \%$, respectively, and an increase in south and southern areas in about $13.7 \%$ and $26.3 \%$. A generalized increase in frost events (2.90\%-16.02\%) took place mainly in the country's northern part. Results showed higher concordance percentages in stations belonging to the Köppen-Geiger type B (dry climate) and C (temperate climate). Thus, an increase in the maximum temperature occurred from north-central to south zones, a decrease in minimum temperature from north to central zone, and an increase in highlands (700-4000 m a.s.l.), central, south, and southern zone of the country. Also, a precipitation decrease and thermal amplitude increased roughly from the Coquimbo Region to the country's central and southern zone. Variations in the agroclimatic indices' behavior can affect yield and production of crops; thus, agroclimatic information presented here can support the zoning and selection of the cropping system.
\end{abstract}

Key words: Agroclimatic indexes, climate change, climate variables, Köppen-Geiger climate, precipitation and temperature trends.

\section{INTRODUCTION}

According to the Fifth Report of the Intergovernmental Panel on Climate Change (IPCC) of 2013, global warming is unequivocal. Many of the changes observed have been unprecedented in recent decades (Hoegh et al., 2018). It had a significant impact on agriculture, manifested itself in the advancement of phenological stages (Wu et al., 2019), more intense drought cycles (Hänsel et al., 2019), and changes in numerous productive aspects (Pathak et al., 2018). Besides, to understand and identify climate change and its impact on agricultural interest species and relate them to organisms' behavior, it is necessary to analyze agroclimatic indexes (Granados Ramírez et al., 2011; Donat et al., 2013).

Agroclimatic indexes are used to reference changes in essential phenological phases, such as sprouting, flowering, and, therefore, harvesting (through the number of frosts and degree day; Back et al., 2014). Also, to relate it with plants' physiological needs (through thermal amplitude, temperature, and precipitation, among others). In complement, it helps decision-making based on the management and implementation of agricultural technologies. 
A series of studies on climate projections under various future greenhouse gas and aerosol emission scenarios have been carried out in Chile (Meza et al., 2012; Sarricolea et al., 2017; Hoegh et al., 2018). These indicate the main effects of climate change: increased temperature, decreased precipitation, and an increase in the frequency of extreme events (floods, droughts), having direct or indirect consequences on productive activities and social and environmental development (IPCC, 2014).

Greenhouse gases act as a "driver" for climate change (Hoegh et al., 2018). However, there are also regular variations in natural factors (geographic and atmospheric) that vary globally. These are the well-known climate action centers (Jáuregui, 2003; Boisier et al., 2016) influencing the country's climate. The South Pacific Anticyclone (SPA) (Saavedra et al., 2011; Poblete et al., 2013), the Polar Anticyclone (High Polar) and its influence on the climatic variability of Antarctic Oscillation (AAO, Quintana and Aceituno, 2012), and Bolivia's High Anticyclone (Méndez González et al., 2010; Sarricolea Espinoza et al., 2014) which influences altiplano through monsoons.

The Köppen-Geiger classification system has been broadly used in climate research because of its simplicity and objectivity in examining climate changes in observations and visualizing projected future changes (Rubel and Kottek, 2010; Chen and Chen, 2013). It identifies a territory's climate behavior through seasonal patterns of temperature and precipitation, but about vegetation/plant growth to define a boundary between one climate and another (Chen and Chen, 2013; Mahlstein et al., 2013; Sarricolea et al., 2017). It allowed characterizing Chilean territory under four major groups (Sarricolea et al., 2017): tropical rainy (A), desert (B), temperate rainy (C), and cold climates (E).

The Köppen-Geiger climate classification has been studied to predict ecosystems' distribution based on monthly values and annual cycles of temperature and precipitation, together with the plant cover's sensitivity (Mahlstein et al., 2013). Also, there is growing interest in identifying changes in climate and vegetation over time both globally (Rubel and Kottek, 2010; Chen and Chen, 2013; Mahlstein et al., 2013; Rohli et al., 2015; Rahimi et al., 2020) and locally (Morales et al., 2006; Orrego et al., 2016).

The generation of predictive models is a crucial tool to foresee the repercussions that climate change could generate in our country (Sarricolea et al., 2017; Hoegh et al., 2018). However, it is also essential to establish a relationship of these dynamics currently observed at a global and regional level with agronomy. In particular, investigate how they may affect agro-climatic variables and help predict the distribution of the most suitable plants and crops throughout the country (Baginsky et al., 2016).

This study investigated the relationship between climate variables and agroclimatic indexes to the Köppen climate classification system. We wanted to identify a significant trend of agroclimatic variables in the climatic zones throughout the country. Following the above, we analyzed the spatial dynamics of the agroclimatic variable trend related to Chile's climate change during 1985-2015. Intrinsically, i.e., to investigate both their value and significance and its spatial consistency to Köppen-Geiger climate classification.

\section{MATERIALS AND METHODS}

We used data records from the Meteorological Direction of Chile (DMC) and the General Water Department (DGA) concerning material. Altogether, 900 official meteorological stations provide daily temperature and rainfall records throughout the country between 1985 and 2015. From there, we finally selected only those that effectively recorded more than $90 \%$ of both the temperature and precipitation data. That gives only 72 meteorological stations throughout the country (Figure 1a). Undoubtedly, it is a reduced number, but robust results require quality over quantity. On the other hand, our work are focused in general trends, and stations show a suitable spatial distribution for it.

Then, for each meteorological station and both the spring-summer season and annually, the following agroclimatic indexes were calculated: Thermal amplitude, frost quantity, and degrees day, based on Donat et al. (2013).

Then, we performed a previous or pre-analysis of descriptive statistics. We noted extreme and anomalous data, and most importantly, we noted that data did not comply with normal distributions. Therefore, we used Spearman's coefficient (Flores et al., 2017) instead of Pearson to determine its statistical significance. We then performed a two-stage analysis; a trends analysis of the different agroclimatic variables and another regarding the agreement with the Köppen-Geiger climate classification (Figure 1b). All statistical analyses were performed through R software (R Foundation for Statistical Computing, Vienna, Austria). 
Figure 1. Study area of this investigation. (a) Chilean Regional Division (with their respective names) and distribution of meteorological stations (in red) used in the study, and (b) Köppen-Geiger climates present in Chile. The types of Köppen climates used correspond to those identified by Sarricolea et al. (2017).
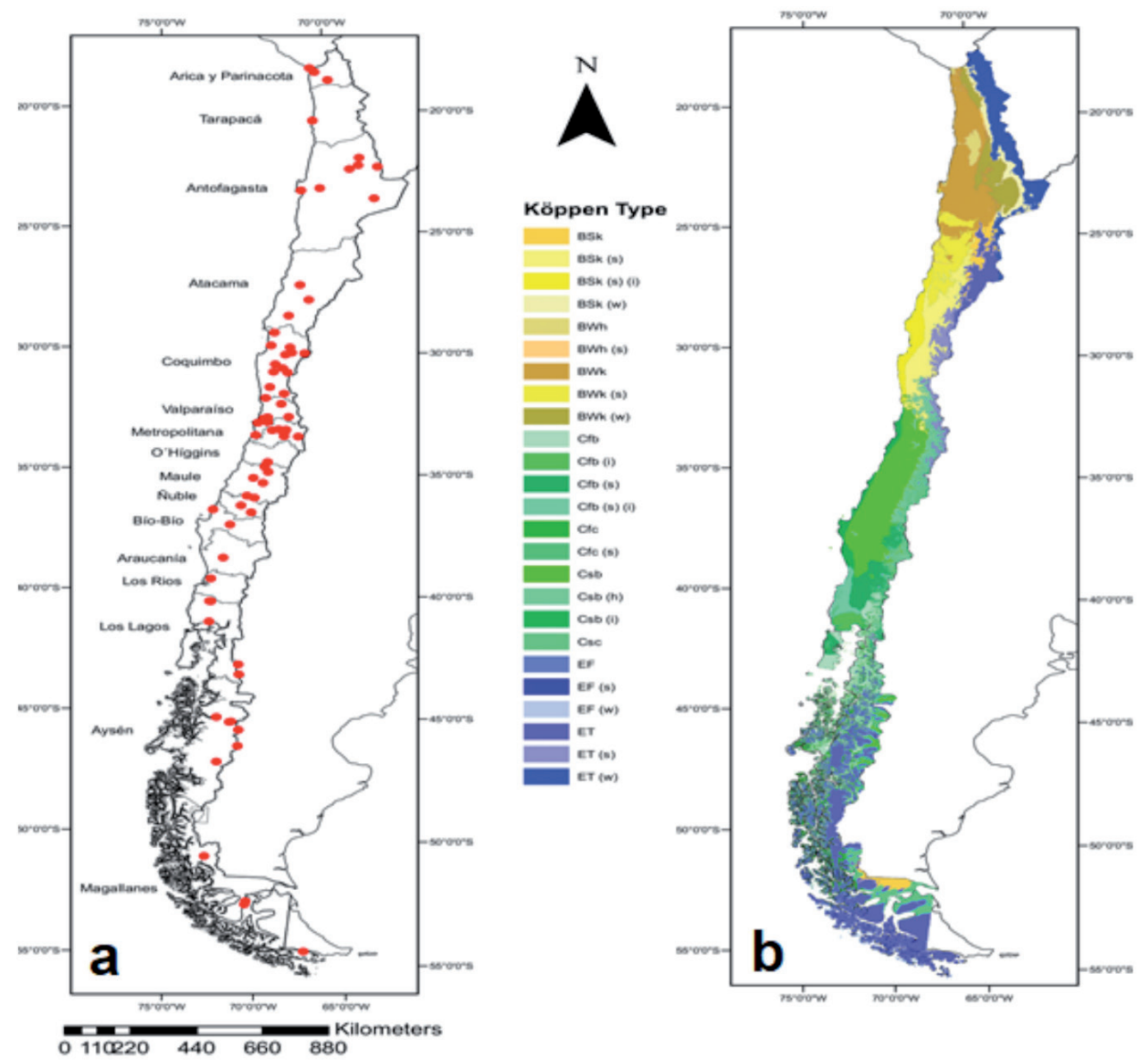

We computed the trend characteristics (descriptive analysis) and their significance (through Spearman coefficient) for each agroclimatic indices and each meteorological station. We then plotted the trend spatial variability (for annual and the spring-summer season) throughout Chile by using the Global Polynomial Interpolation (GPI) method (Artigas, 2016). This method allows an approximation of the study area's general trend and thus excludes local effects (Wang et al., 2014). Although global polynomial interpolation is not the better method for represent the local spatial trends in Chile, due to the high climate variability due to its complex topography, it is a good method to identify general trends at atmospheric drivers scale. This method was used in other research for maping climate spatial trends (Booth et al, 2012).

We used the spatial distribution of Köppen-Geiger climate types for Chile, updated by Sarricolea et al. (2017) (Figure 1a). It is a $1 \times 1 \mathrm{~km}$ resolution grid map, at a 1:2000000 scale extracted from the Infraestructure of Geospatial Data (IDE) Chile database (http://www.ide.cl/). The meteorological stations were classified based on their location regarding the Köppen climate (Figures 1a, 1b). Then, within each climate zone, the total number of positive or negative trends obtained by Mann-Kendall test performed in trends analisys, was counted. It allowed determining the percentage of positive or negative trends about the total number of stations per zone. Suppose the percentage calculated is greater than $50 \%$. In that case, and only under that condition, "agreement" occurs between the variable's behavior and the climate zone. Thus, much of the climate zone follows that trend. Inversely, if it is less than 50\%, "disagreement" occurs. Besides, we also computed the percentage of missing data for each variable. For reasons of statistical robustness, when this occurs, "no agreement" also occurs. At last, with trends (up or down) and agreement values, maps were produced for each variable and Köppen classification. 


\section{RESULTS AND DISCUSSION}

The results found are detailed in two stages, as described above. First, we analyze agroclimatic variables' tendencies (thermal amplitude, degrees day, frost, maximum and minimum temperature, and precipitation). Then we perform an analysis of Köppen-Geiger's climatic classification trends and their behavior. Both are shown in detail throughout Chile.

\section{Trend analysis of agroclimatic variables}

For thermal amplitude, spring-summer season trends' agroclimatic variables (Figure 2) show a generalized decrease in the country's thermal amplitude by $12.9 \%$. However, it also shows an increase in the mountainous area from the Atacama Region ( $26^{\circ} \mathrm{S}$ lat) to the Libertador General Bernardo O'Higgins Region ( $35^{\circ} \mathrm{S}$ lat) by $7.2 \%$ (Figure 2$)$. An increase in the

Figure 2. Trends in agroclimatic variables concerning the spring-summer season.

Thermal amplitude
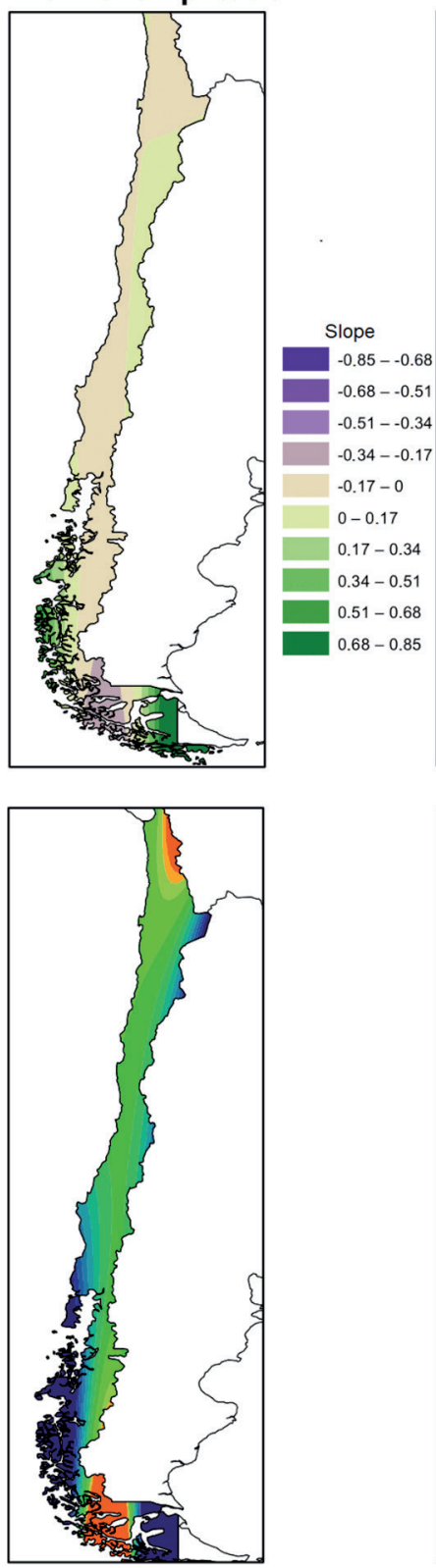

Degrees day
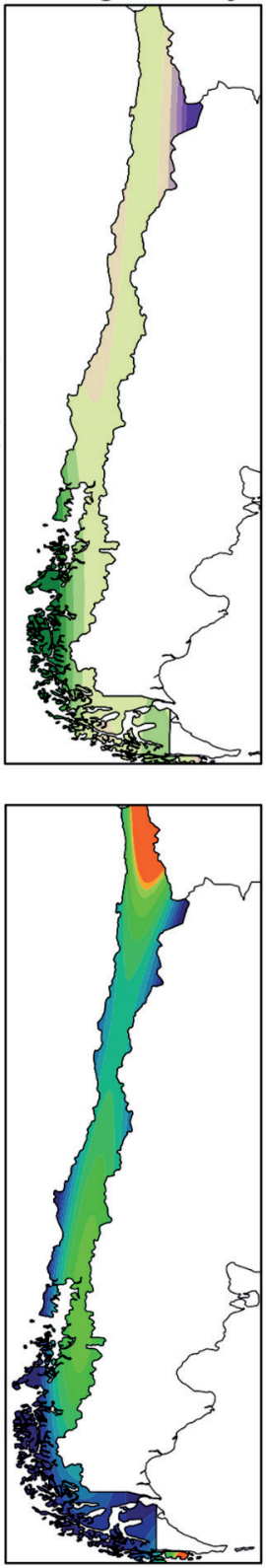

Frosty days
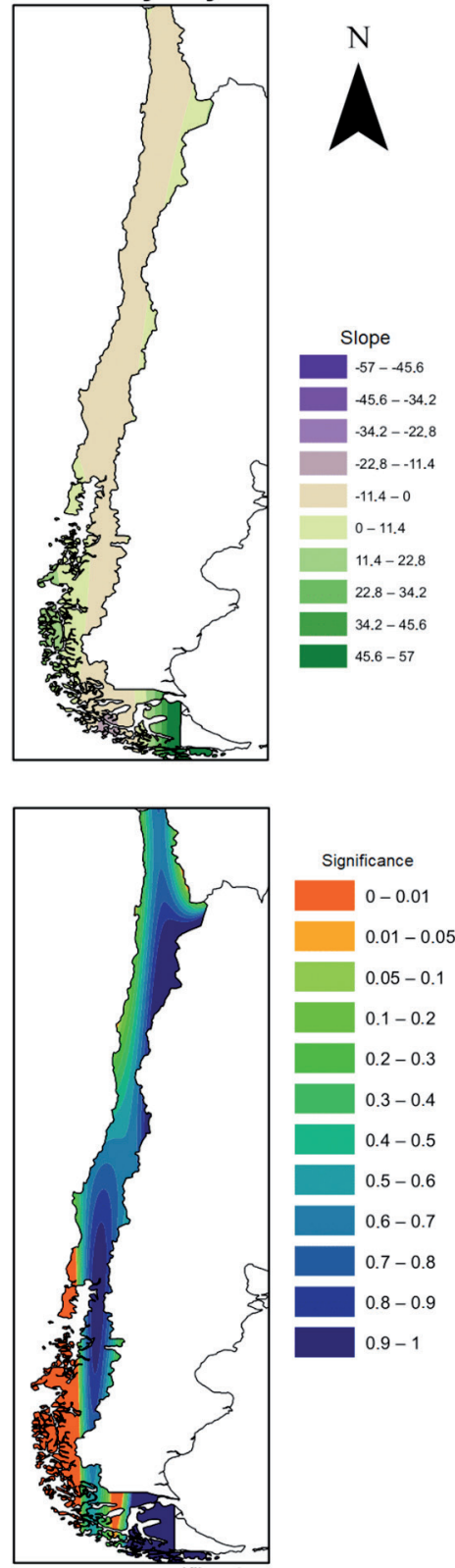
maximum temperature and thermal amplitude can cause more significant water stress or reductions in photosynthetic rates (Baginsky et al., 2016), reducing crop yield (Granados Ramírez et al., 2011; Meza et al., 2012). The associated decrease in minimum temperature can also produce crop damage and even death. However, we also see a $20 \%$ decrease in the central zone's thermal amplitude (Table 1). It suggests favorable conditions to produce crops suitable for the associated environmental condition.

On the other hand, the results show a decrease in day degrees in the coastal zone of $6.9 \%$ (Figure 2). It goes from Coquimbo Region ( $29^{\circ} 20^{\prime} \mathrm{S}$ lat) to Nuble Region ( $37^{\circ} 12^{\prime} \mathrm{S}$ lat), part of the altiplano zone ( $17^{\circ} 45^{\prime}$ to $26^{\circ} \mathrm{S}$ lat), and $4.4 \%$ in the country's interior and mountainous zone (Figure 2). This index allows estimating plant development and predicting the harvest date of crops based on physiological maturity; thus, each crop variety has unique values.

For frost days, a not very significant decrease (nearly $0.7 \%$ ) occurs in a large part of the national territory, except for the high plateau area, where an increase of $17.9 \%$ occurs (Figures 2 and 3). The incidence of frost also has adverse effects on the productive system. Thus, besides causing crop yield losses (Chang et al., 2014; Baginsky et al., 2016), it can also limit their geographical distribution. It also damages photosynthetic processes, efficiency, and plant structure (Chang et al., 2014; Baginsky et al., 2016). Therefore, the decrease in frost and the decrease in thermal amplitude could generate changes in the choice and production of varieties in an area.

\section{Trend analysis of temperature and precipitation}

Northern zone shows a slight increase in the maximum temperature (3.9\%) and a striking decrease in the minimum temperature (30\%). It shows an increase in precipitation (7.3\%) except for the plateau zone (Figure 3, Table 1). This research agrees with other research works such as those by Vuille et al. (2015) who showed slight cooling trends in the northern area, particularly along the coasts, showing a decreasing trend in the northern's maximum temperature.

The South Pacific Anticyclone (Poblete et al., 2013; Hoegh et al., 2018) and its interaction with the Humboldt Current influence the northern zone. Thus, the emergence of colder deep waters contributes to decreasing the coastal oceanic waters' evaporation capacity (Garcés-Vargas and Abarca-del-Río, 2012). The different interactions generated within the zone cause a decrease in the sea's surface temperature, cooling the adjacent air masses and increasing wind circulation speed. It could explain why the northern zone, in the coastal area, shows a decrease in temperature trends (Figure 4). It is also well known that the Bolivia's High influences the Altiplano (Méndez González et al., 2010; Sarricolea Espinoza et al., 2014). It increases in intensity and increases warm air masses' transfer with humidity through the South American Monsoon, especially in summer. This condition could explain the trend of increased precipitation in the area (Figure 4).

There was a $2.3 \%$ increase in maximum temperature in the country's central zone regarding the northern zone, a 5.9\% increase in minimum temperatures, and a 7.32\% decrease in precipitation (Table 1). Quintana and Aceituno (2012) and Bozkurt et al. (2017) coincide regarding negative trends in precipitation, increase in maximum and minimum temperature, and a decrease in the number of frosts. The South Pacific Anticyclone acts as a barrier to frontal systems associated with rainfall in the country's central and southern parts. Some studies have shown that the Hadley Cell is expanding, implying a southward displacement of the anticyclone (Saavedra et al., 2011; Hoegh et al., 2018). Thus, subtropical areas are progressively dry, increasing the probability of drought (Boisier et al., 2016). It may explain why the country's centralsouth zone results show increased temperature and decreased precipitation trends (Figure 4).

Table 1. Percentage of trends in agroclimatic variables according to each zone.

\begin{tabular}{|c|c|c|c|c|c|c|c|}
\hline \multirow[b]{2}{*}{ Zona } & \multicolumn{7}{|c|}{ Agroclimatic variable (\%) } \\
\hline & Location (S lat) & Amp & Gra & $\mathrm{He}$ & Tmax & Tmin & $\mathrm{Pp}$ \\
\hline Great North & $19^{\circ} 13^{\prime}-26^{\circ} 05^{\prime}$ & -12.0351 & -20.3979 & +16.0246 & +3.9311 & -30.1420 & +7.3260 \\
\hline Small North & $26^{\circ} 00^{\prime}-32^{\circ} 15^{\prime}$ & +6.6330 & +13.5803 & +0.6723 & -0.0133 & +12.7956 & -61.8429 \\
\hline Center & $32^{\circ} 02^{\prime}-38^{\circ} 29^{\prime}$ & -20.3108 & -13.9160 & +7.6186 & +2.2781 & +5.9385 & -7.7142 \\
\hline South & $37^{\circ} 35^{\prime}-44^{\circ} 03^{\prime}$ & +13.7716 & +17.3579 & +8.3980 & +0.0912 & +5.4121 & -10.7223 \\
\hline Southern & $43^{\circ} 38^{\prime}-56^{\circ} 30^{\prime}$ & +26.2880 & +12.1709 & 2.9079 & -12.1171 & -4.4839 & +0.8303 \\
\hline Total (average) & & +2.8693 & 1.7590 & 7.1243 & -1.166 & -2.5020 & -14.425 \\
\hline
\end{tabular}

Amp: Thermal amplitude; Gra: degrees day; He: frost; Tmax: maximum temperature; Tmin: minimum temperature; Pp: precipitation.

Values with a (-) sign indicate a decrease. Values with a (+) sign indicate an increase. 
Figure 3. Agroclimatic indexes trends: Slope (above) and significance (below).

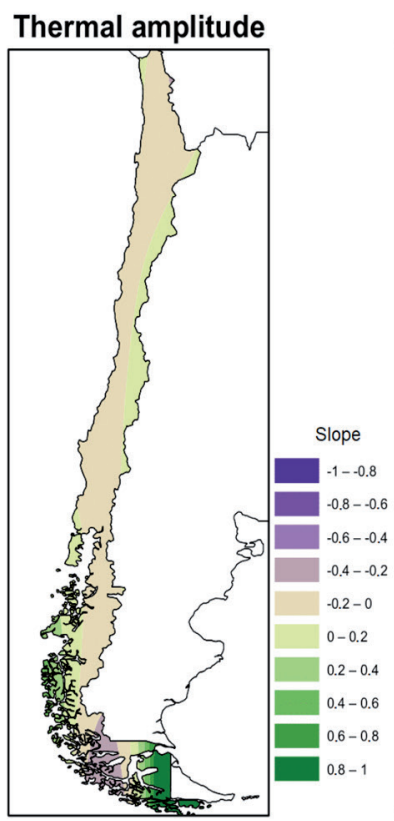

Degree days

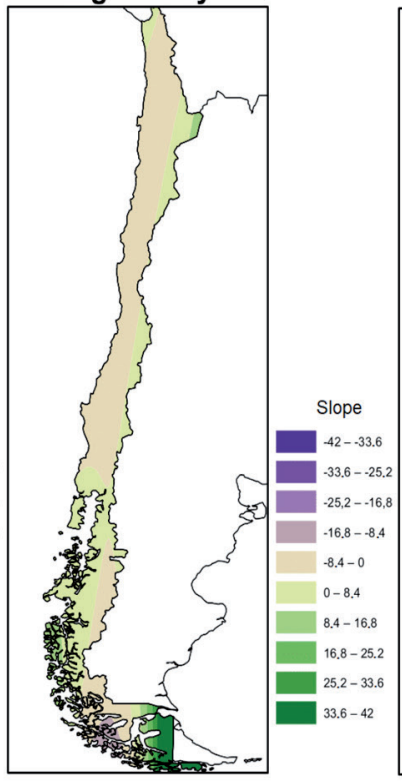

Frost days

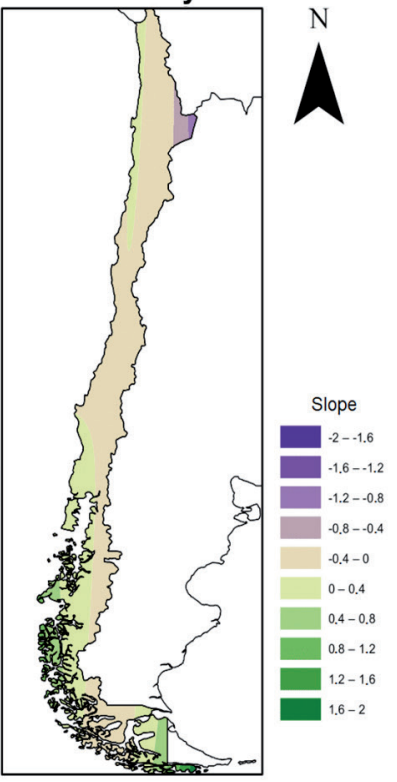

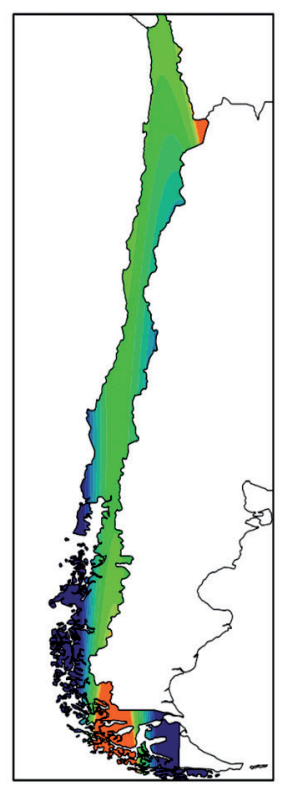
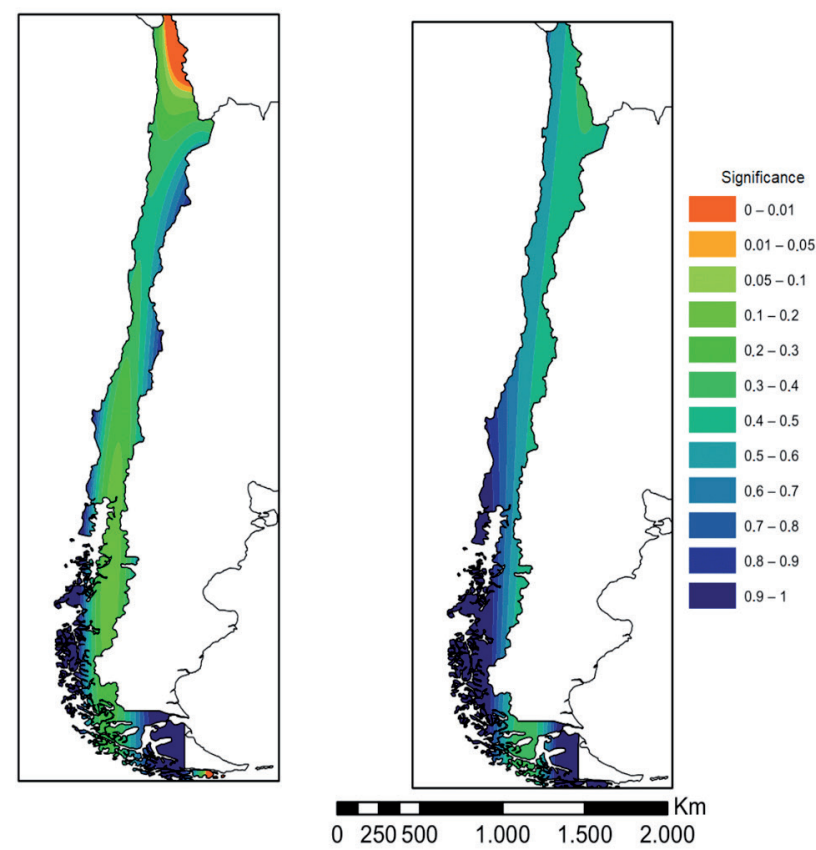

The southern zone does not show a significant maximum temperature increase: it is only $0.09 \%$. Instead, it decreases $13.07 \%$ in minimum temperatures up to the Nuble Region ( $36^{\circ} 00^{\prime}$ to $37^{\circ} 12^{\prime} \mathrm{S}$ lat) and increases from the Biobío Region; $5.41 \%$. Besides, a decrease in precipitation of $10.7 \%$, essentially in the interior of the Biobío Region and Los Lagos Region, occurs (Figure 4, Table 1).

Southern-austral zone shows a decrease of $12.2 \%$ of the maximum temperature in the mountainous zone of the austral zone and a general decrease of $4.5 \%$ of minimum temperature. Instead, the precipitation increases by $0.83 \%$ but is nonsignificant (Figure 4, Table 1). Here, the Antarctic Oscillation's influence plays a significant role. It allows many frontal systems to cross in the continent's south, explaining the increase in rainfall (Quintana and Aceituno, 2012) (Figure 4). 
Figure 4. Climate variable trends: Slope (above) and significance (below).

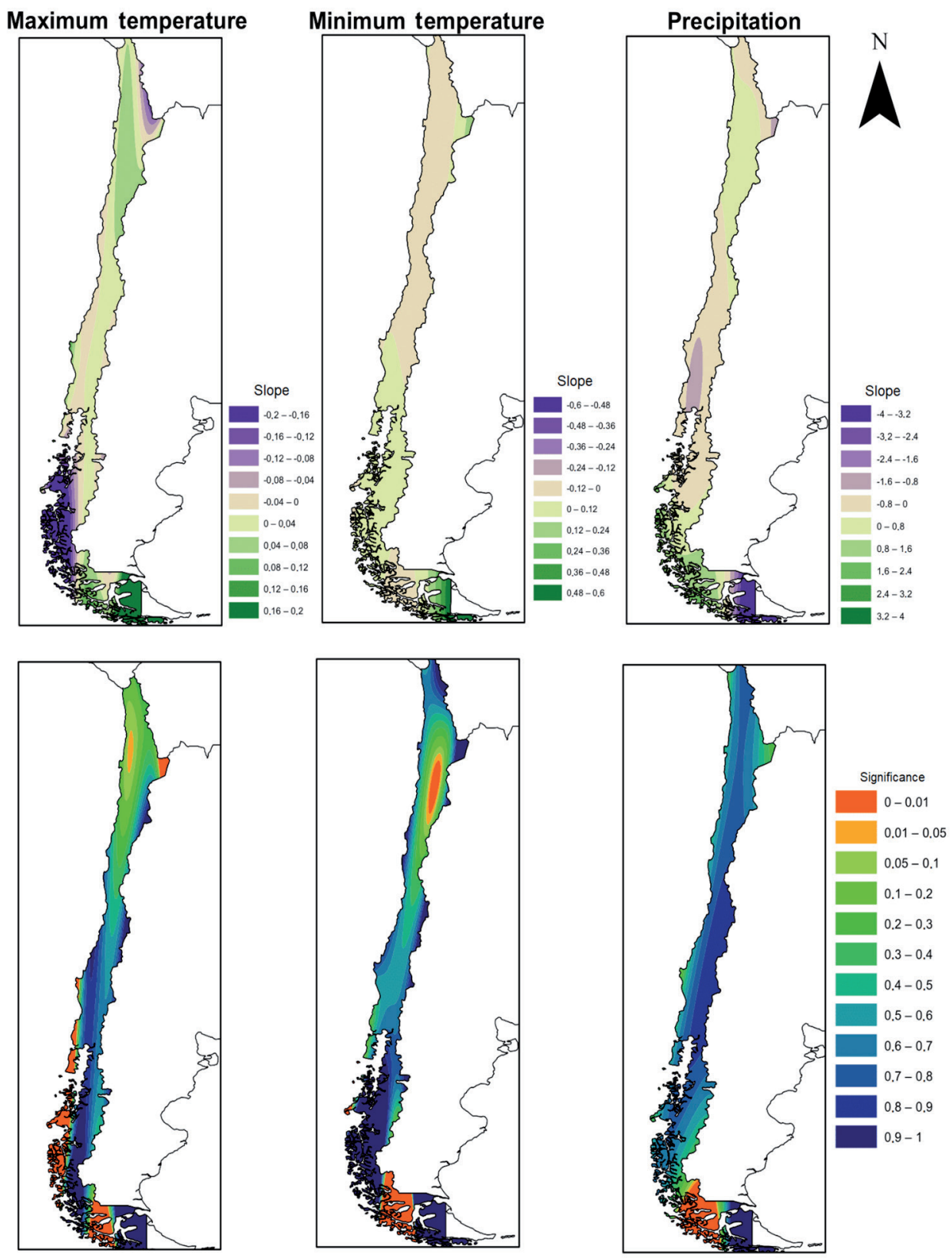

Also, it shows an increase in maximum temperature and rainfall in the southern austral zone, with slight increases in the minimum temperature recorded. Note that they also point out that given that there is so little information about climatic variables in the southern part of the country, it renders general trends depiction difficult.

It is essential to note that the most significant areas are in the highlands and the country's southern part (Figures 3 and 4). Instead, the non-significance of many other areas can have multiple reasons. The most important are related to extreme values generating noise in variables behavior and length of the time series. Other factors at higher spatial and temporal resolutions, such as atmospheric rivers, may also have played a role influence (Guan and Waliser, 2015) or more global such as Mount Pinatubo's eruption in the Philippines during 1991 (English et al., 2013) or influence of the El NiñoSouthern Oscillation. 


\section{Analysis according to the Köppen-Geiger climate classification}

The agroclimatic variables' behavior to each Köppen-Geiger climate is presented in Tables 2 and 3. It shows the tendencies and agreement percentage of each distribution as visualized in Figures 3 and 4. According to each climate type's predominant surface in the Chilean territory, results are presented, describing the agroclimatic tendencies and distribution. Lastly, a bibliographical review suggests explaining factors that may affect the climatic variability of the areas based on the agreement level.

Table 2. Agreement level of agroclimatic variables to Köppen-Geiger classification.

\begin{tabular}{|c|c|c|c|c|c|}
\hline \multirow[b]{2}{*}{ Köppen climate } & \multirow[b]{2}{*}{ Nr of stations } & \multirow[b]{2}{*}{ Total data } & \multicolumn{3}{|c|}{ Agreement level (\%) } \\
\hline & & & Agreement & Disagreement & No agreement \\
\hline $\mathrm{AF}$ & 1 & & & Insufficient data available & \\
\hline BSk (s) & 15 & 480 & 61.04 & 34.17 & 4.79 \\
\hline BSk (s) (i) & 2 & 56 & 57.14 & 35.71 & 7.14 \\
\hline $\mathrm{BWh}$ & 3 & 96 & 36.46 & 35.42 & 28.13 \\
\hline BWk & 2 & 56 & 55.36 & 41.07 & 3.57 \\
\hline BWk (s) & 1 & & & Insufficient data available & \\
\hline BWk (w) & 5 & 160 & 53.75 & 37.50 & 8.75 \\
\hline $\mathrm{Cfb}$ & 5 & 160 & 45.63 & 46.88 & 7.50 \\
\hline Cfb (i) & 1 & & & Insufficient data available & \\
\hline $\mathrm{Cfb}(\mathrm{s})$ & 3 & 96 & 55.21 & 41.67 & 3.13 \\
\hline $\mathrm{Cfc}$ & 1 & & & Insufficient data available & \\
\hline $\mathrm{Csb}$ & 22 & 704 & 52.13 & 46.02 & 1.85 \\
\hline Csb (h) & 1 & & & Insufficient data available & \\
\hline Csb (i) & 3 & 96 & 55.21 & 44.79 & 0.00 \\
\hline Csc & 3 & 96 & 51.04 & 27.08 & 21.88 \\
\hline $\mathrm{EF}$ & 1 & & & Insufficient data available & \\
\hline ET & 1 & & & Insufficient data available & \\
\hline ET (s) & 1 & & & Insufficient data available & \\
\hline $\mathrm{ET}(\mathrm{w})$ & 1 & & & Insufficient data available & \\
\hline
\end{tabular}

The types of Köppen climates used correspond to those identified by Sarricolea et al. (2017).

Table 3. Behavior of agroclimatic variables according to Köppen-Geiger classification.

\begin{tabular}{|c|c|c|c|c|c|c|c|c|c|c|}
\hline \multirow[b]{2}{*}{$\begin{array}{l}\text { Köppen } \\
\text { climate }\end{array}$} & \multirow[b]{2}{*}{$\begin{array}{c}\mathrm{Nr} \text { of } \\
\text { stations }\end{array}$} & \multirow[b]{2}{*}{$\begin{array}{l}\text { Total } \\
\text { data }\end{array}$} & \multicolumn{8}{|c|}{ Trend } \\
\hline & & & Tmax & Tmin & $\mathrm{Pp}$ & Amp & Gra & $\mathrm{He}$ & $\mathrm{Pp}>10$ & $\operatorname{Tmax}>27$ \\
\hline $\mathrm{AF}$ & 1 & & \multicolumn{8}{|c|}{ Insufficient data to determine trends } \\
\hline BSk (s) & 15 & 480 & + & - & - & + & + & - & + & + \\
\hline BSk (s) (i) & 2 & 56 & + & + & - & & & + & + & + \\
\hline $\mathrm{BWh}$ & 3 & 96 & - & + & + & - & - & & + & - \\
\hline BWk & 2 & 56 & & - & & & - & - & & + \\
\hline BWk (s) & 1 & & \multicolumn{8}{|c|}{ Insufficient data to determine trends } \\
\hline BWk (w) & 5 & 160 & + & + & - & + & + & - & + & + \\
\hline $\mathrm{Cfb}$ & 5 & 160 & + & + & & & - & - & & \\
\hline Cfb (i) & 1 & & \multicolumn{8}{|c|}{ Insufficient data to determine trends } \\
\hline $\mathrm{Cfb}(\mathrm{s})$ & 3 & 96 & + & + & & + & + & + & - & + \\
\hline Cfc & 1 & & \multicolumn{8}{|c|}{ Insufficient data to determine trends } \\
\hline $\mathrm{Csb}$ & 22 & 704 & + & + & - & + & & - & - & + \\
\hline Csb (h) & 1 & & \multicolumn{8}{|c|}{ Insufficient data to determine trends } \\
\hline Csb (i) & 3 & 96 & & & & + & + & - & - & + \\
\hline Csc & 3 & 96 & + & + & + & + & + & - & + & + \\
\hline $\mathrm{EF}$ & 1 & & \multicolumn{8}{|c|}{ Insufficient data to determine trends } \\
\hline ET & 1 & & \multicolumn{8}{|c|}{ Insufficient data to determine trends } \\
\hline ET (s) & 1 & & \multicolumn{8}{|c|}{ Insufficient data to determine trends } \\
\hline ET (w) & 1 & & \multicolumn{8}{|c|}{ Insufficient data to determine trends } \\
\hline
\end{tabular}

The types of Köppen climates used correspond to those identified by Sarricolea et al. (2017).

Tmax: Maximum temperature; Tmin: minimum temperature; Pp: precipitation; Amp: Thermal amplitude; Gra: degrees day; He: frost; Values with a (-) sign indicate a decrease. Values with a (+) sign indicate an increase. 
According to Sarricolea et al. (2017), Köppen's predominant classification present in the country is the temperate climate (C), with a surface of $41 \%$ of the total Chilean territory. This classification presents the highest number of stations (37 stations). The temperate climate (Table 2) analysis shows a generalized increase of maximum and minimum temperatures in different subcategories (Cfb, $\mathrm{Cfb}(\mathrm{s}), \mathrm{Csb}, \mathrm{Csb}(\mathrm{i})$ ). These extend from the south zone of the Coquimbo ( $29^{\circ} 20^{\prime} \mathrm{S}$ lat) to Magallanes y la Antártica Chilena (56 $30^{\circ}$ S lat) Regions. All that except the southern zone, interspersed with cold climates (E), many archipelagos, and ice formation's permanent action.

We can also observe that the type $\mathrm{C}$ climate presents a general decrease in the number of frosts. Although except for temperate rainy climate with slight summer dryness (type $\mathrm{Cfb}(\mathrm{s})$ ), which shows an increase in the number of frosts. This last situation is present principally in Los Ríos and Los Lagos Regions (Figure 5). Also, Table 3 shows a decrease in precipitation, essentially in the Mediterranean winter rain climate (Csb zone), with 52.13\% agreement on the trend (Table 2, Figure 5). It means that the decrease in the trend is slight compared to the recorded data. Also, there is an increase in the thermal amplitude and degrees per day (Table 3 ).

On the other hand, the dry climate (type B) covers $31 \%$ of the Chilean territory's surface area (Sarricolea et al., 2017). It goes from Arica and Parinacota Region (17 $30^{\prime} \mathrm{S}$ lat) to the Coquimbo Region ( $32^{\circ} 15^{\prime} \mathrm{S}$ lat), including the Valparaíso and Metropolitana Regions interior zones. Note also that this climatic zone covers the most considerable amount of information: 28 meteorological stations. Concerning the behavior of type B climate trends, there is an increase in maximum temperature, minimum temperature, thermal amplitude, and degrees day (Figure 5) and a general decrease in precipitation (Table 3), except for the hot desert climate type (type BWh). The BWh climate type is found along the coastal edge (Table 3, Figure 5). It presents a decrease in maximum temperature, increased minimum temperature, and precipitation. Instead, it shows a decrease in thermal amplitude and degrees day (Figure 5), presenting a $36.46 \%$ trend agreement (Table 2).

Figure 5. Trends of climatic and agroclimatic variables concerning the Köppen climate zones.

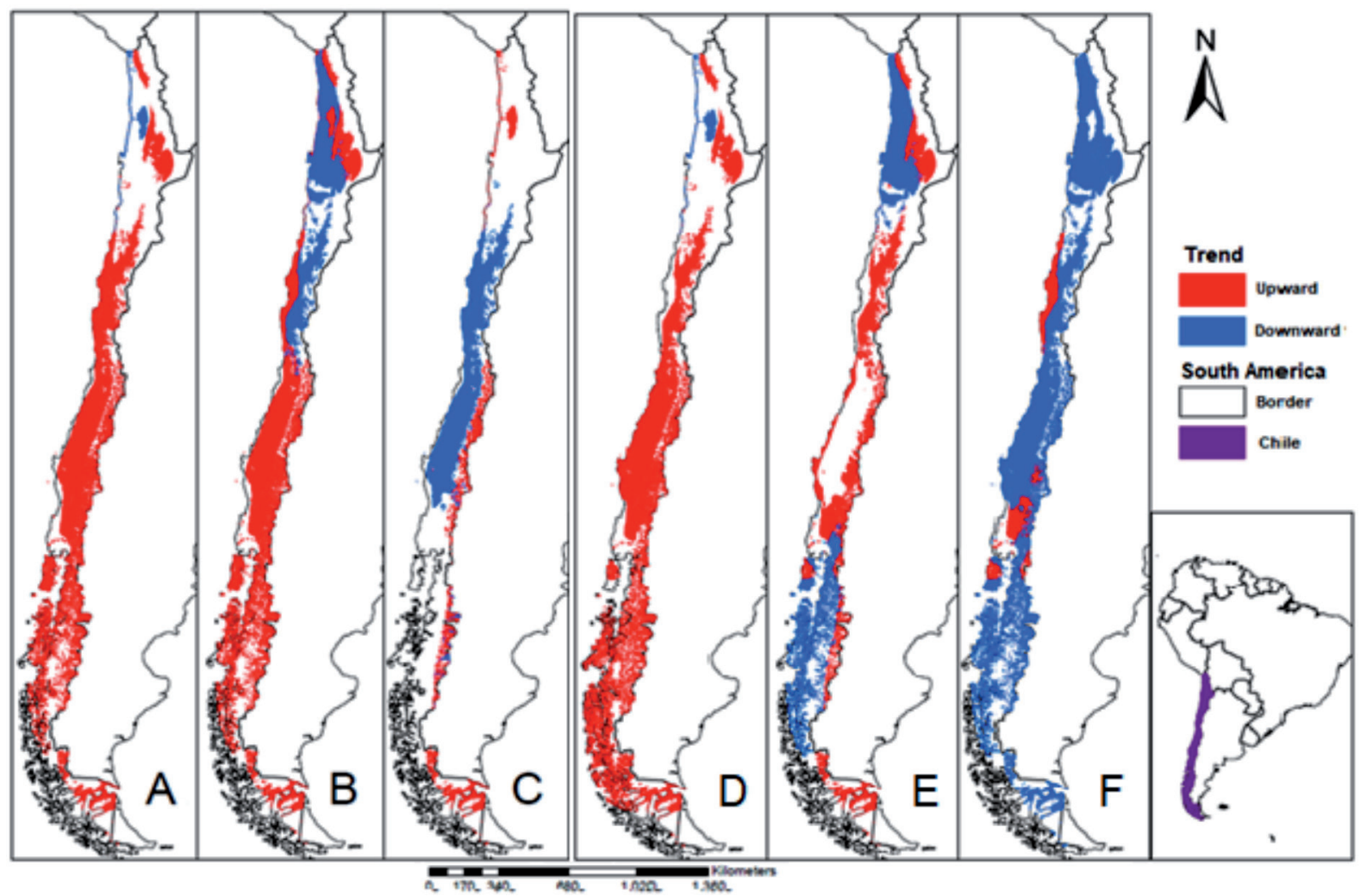

A: Maximum temperature; B: minimum temperature; C: precipitation; D: thermal amplitude; E: degree days; F: frost days. The red color represents positive trends and the blue color negative trends. 
We note that the arid winter rainfall climate and coastal influence $(\mathrm{BSk}(\mathrm{s})(\mathrm{i})$ zone) presents differences from the generalized behavior of climate type B. There is an increase in minimum temperature and the number of frosts (Table 3 ). It presents a $57.14 \%$ agreement compared to $35.71 \%$ disagreement (Table 2), supporting the data's significance.

The classification of cold climates (type E) involves $28 \%$ of the Chilean surface area (Sarricolea et al., 2017). It is present in the mountainous zone throughout Chile and the insular zone of the Magallanes y la Antártica Chilena Region. However, the lack of stations in cold climates (E) areas impedes establishing a significant relationship for the percentage of agreement and disagreement.

In summary, the analysis according to the Köppen climate classification shows a higher percentage of agreement overall only for meteorological stations belonging to the Köppen-Geiger type B (dry climate) and C (temperate climate). Accordingly, the generated maps show an increase in maximum temperature from the central north $\left(19^{\circ} 13^{\prime} \mathrm{S}\right.$ lat) to the south ( $44^{\circ} 03^{\prime} \mathrm{S}$ lat) of the country, a decrease in minimum temperature from the north (19 $19^{\circ}$ ' $\mathrm{S}$ lat) to the central zone $\left(38^{\circ} 29^{\prime} \mathrm{S}\right.$ lat), with an increase in temperature in the highlands $\left(18^{\circ}-27^{\circ} \mathrm{S}\right.$ lat, $3700-4000 \mathrm{~m}$ a.s.1.), and an increase in the central-south zone (32 $02^{\prime}-38^{\circ} 29^{\prime} \mathrm{S}$ lat) (Figure 5). It also shows an increase in thermal amplitude from the Coquimbo

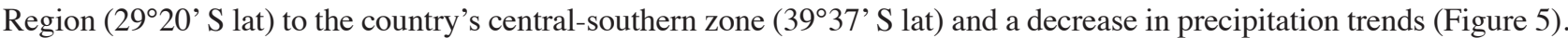

Based on the levels of agreement and also following the work of Chen and Chen (2013), a more remarkable agreement of the climatic variables in the Köppen areas may be related to a variation in the climate's intensity action centers. Thus, the variables' trends increase or decrease within the same climatic zone (Figure 5) following its intensity. Also, low or no agreement may occur because of interdecadal variability in climate normal (Chen and Chen, 2013) reflected in the climate action centers' position and size changes.

Inversely, areas with no agreement level (Figure 5) are probably related to a change in the climate action centers' position and size. Thus, if the South Pacific Anticyclone changes its position (Saavedra et al., 2011), it displaces high temperatures' climatic tendencies and produces a decrease in precipitation towards the country's southern zone. Lastly, one cannot leave aside other influences. For example, a lower agreement percentage may also be related to other factors such as atmospheric rivers (Guan and Waliser, 2015) and the Madden-Julian Oscillation (Zhang, 2013; Boisier et al., 2016).

The results presented here are a tool for farmers and related professionals. It provides an orientation for management decisions, planning, and mitigation of potential damage to crops caused by climatic events. In agriculture, the phenological stage of many species' crops is susceptible to atmospheric events occurrence. These can cause irreparable economic damage. Variations in agroclimatic indexes' behavior can affect crop yield and production. When establishing sowing, it is convenient to know the approximate date of harvest of the crop produced; it varies according to environmental conditions, for example, the temperature that affects crop yield. Thus, agroclimatic information can support the selection, zoning, and cultivation system choice.

\section{CONCLUSIONS}

Our analysis of agroclimatic variables' trends shows an increase (between 0.09\%-3.9\%) in maximum temperature from the north to the south of Chile $\left(19^{\circ} 13^{\prime}-44^{\circ} 3^{\prime} \mathrm{S}\right.$ lat). Instead, the maximum temperature decreases $(12.2 \%)$ in the southern zone $\left(43^{\circ} 38^{\prime}-56^{\circ} 30^{\prime} \mathrm{S}\right.$ lat). Concerning the minimum temperature, a decrease takes place in the northern zone (30\%) and southern zone (4.5\%) of the country, and an increase in the central (5.9\%) and southern zones (5.4\%). Precipitation increases in the northern zone (7.3\%) and decreases in central (7.3\%) and southern (10.7\%) zones. The thermal amplitude shows a decrease in the northern (12.03\%) and central (20.3\%) zones and an increase in the south $\left(37^{\circ} 35^{\prime}-44^{\circ} 3^{\prime} \mathrm{S}\right.$ lat) $(13.7 \%)$ and southern $\left(43^{\circ} 38^{\prime}-56^{\circ} 30^{\prime} \mathrm{S}\right.$ lat $)(26.3 \%)$ zones of the country. In addition, the results show a general increase in frost events (2.90\%-16.02\%), mostly located in the country's northern zone. There are several station with nonsignificant trends, many of them are located on the country's southern part, and could be explicated by several unconsidered factors such as volcano eruption, as Pinatuvo in 1992, or the atmospheric rivers which apparently are currently most common.

On the other hand, observing the behavior of agro-climatic variables and their level of agreement concerning each Köppen climate, our results show higher agreement percentages in Köppen-Geiger type B (dry), and C (temperate) climates. Other climatic zones present lesser agreement, although meaningful or no agreement. However, note the following. First, a somewhat limited number of stations were chosen, with only 72 of the 900 available; however, only these met the required quality conditions. Second, our way of measuring the agreement's significance was drastic, it 
depends a lot on the number of stations per climatic zone and, of course, on the spatial coverage. It should also not be forgotten that weather stations' spatial coverage is inadequate and inhomogeneous in Chile. It is the case in the southern zones. Thus, even if a correspondence value is not meaningful neither significant, these are still values that could be very interesting for many people.

\section{REFERENCES}

Artigas, J.M. 2016. Análisis de la influencia del cambio climático en las necesidades de climatización en Andalucía a escala de detalle territorial. 193 p. Tesis Doctoral. Universidad de Sevilla, Departamento de Geografía Física y Análisis Geográfico Regional, Sevilla, España.

Back, Á.J., Della Bruna, E., e Felipetto, J. 2014. Tendências nos índices climáticos e agroclimáticos aplicados à videira no Planalto Serrano de Santa Catarina. Revista Brasileira de Climatologia 13:138-148.

Baginsky, C., Arenas, J., Escobar, H., Garrido, M., Valero, N., Tello, D., et al. 2016. Growth and yield of chia (Salvia hispanica L.) in the Mediterranean and desert climates of Chile. Chilean Journal of Agricultural Research 76:255-264.

Boisier, J.P., Rondanelli, R., Garreaud, R.D., and Muñoz, F. 2016. Anthropogenic and natural contributions to the Southeast Pacific precipitation decline and recent megadrought in central Chile. Geophysical Research Letter 43(1):413-421.

Booth, E.L., Byrne, J.M., and Johnson, D.L. 2012 . Climatic changes in western North America, 1950-2005. International Journal of Climatology 32(15):2283-2300.

Bozkurt, D., Rojas, M., Boisier, J.P., and Valdivieso, J. 2017. Climate change impacts on hydroclimatic regimes and extremes over Andean basins in central Chile. Hydrology and Earth System Sciences Discussions 2017:1-29.

Chang, D., Sohn, H., Cho, J., Im, J., Jim, Y., Do, G., et al. 2014. Freezing and frost damage of potato plants: A case study on growth recovery, yield response, and quality changes. Potato Research 57(2):99-110.

Chen, D., and Chen, H.W. 2013. Using the Köppen classification to quantify climate variation and change: An example for 1901-2010. Environmental Development 6:69-79.

Donat, M.G., Alexander, L.V., Yang, H., Durre, I., Vose, R., Dunn, R.J.H., et al. 2013. Updated analyses of temperature and precipitation extreme indices since the beginning of the twentieth century: The HadEX2 dataset. Journal of Geophysical Research: Atmospheres 118(5):2098-2118.

English, J.M., Toon, O.B., and Mills, M.J. 2013. Microphysical simulations of large volcanic eruptions: Pinatubo and Toba. Journal of Geophysical Research: Atmospheres 118(4):1880-1895.

Flores, E., Miranda-Novales, M.G., and Villasís-Keever, M.A. 2017. The research protocol VI: How to choose the appropriate statistical test. Inferential statistics. Revista Alergia México 64(3):364-370.

Garcés-Vargas, J., and Abarca-del-Río, R. 2012. The surface heat fluxes along the eastern Pacific coast from $10 \mathrm{~N}$ to $40 \mathrm{~S}$. Australian Meteorological and Oceanographic Journal 62(2):71.

Granados Ramírez, R.G., Aguilar Sánchez, G.A., Díaz Padilla, G.D., y Medina Barrios, M.D.L.P.M. 2011. Alteraciones de los indicadores agroclimáticos en años con presencia del fenómeno El Niño en la región Centro-Occidente de México. Revista Geográfica de América Central 2:1-16.

Guan, B., and Waliser, D.E. 2015. Detection of atmospheric rivers: Evaluation and application of an algorithm for global studies. Journal of Geophysical Research: Atmospheres 120(24):12514-12535.

Hänsel, S., Ustrnul, Z., Łupikasza, E., and Skalak, P. 2019. Assessing seasonal drought variations and trends over Central Europe. Advances in Water Resources 127:53-75.

Hoegh, O., Jacob, D., Taylor, M., Bindi, M., Brown, S., Camilloni, I., et al. 2018. Impacts of $1.5^{\circ} \mathrm{C}$ global warming on natural and human systems. In Masson-Delmotte, V., Zhai, P., Pörtner, H.-O., et al. (eds.) Global Warming of $1.5^{\circ} \mathrm{C}$. An IPCC Special Report on the impacts of global warming of $1.5^{\circ} \mathrm{C}$ above pre-industrial levels and related global greenhouse gas emission pathways, in the context of strengthening the global response to the threat of climate change, sustainable development, and efforts to eradicate poverty. Intergovernmental Panel on Climate Change (IPCC), Geneva, Switzerland.

IPCC. 2014. Cambio climático 2014: Informe de síntesis. Contribución de los grupos de trabajo I, II, III, al Quinto Informe de Evaluación del Grupo Intergubernamental de Expertos sobre el Cambio Climático In Pachauri, R.K., y Meyer, L.A. (eds.) Intergovernmental Panel on Climate Change (IPCC), Ginebra, Suiza.

Jáuregui, E. 2003. Algunos conceptos modernos sobre la circulación general de la atmósfera. Investigaciones Geográficas 50:121-143

Mahlstein, I., Daniel, J.S., and Solomon, S. 2013. Pace of shifts in climate regions increases with global temperature. Nature Climate Change 3(8):739-743.

Méndez González, J., Ramírez, A., Cornejo, E., Zárate, A., y Cavazos, T. 2010. Teleconexiones de la Oscilación Decadal del Pacífico (PDO) a la precipitación y temperatura en México. Investigaciones Geográficas 73:57-70.

Meza, F.J., Wilks, D.S., Gurovich, L., and Bambach, N. 2012. Impacts of climate change on irrigated agriculture in the Maipo Basin, Chile: reliability of water rights and changes in the demand for irrigation. Journal of Water Resources Planning and Management 138(5):421-430. 
Morales, L., Canessa, F., Mattar, C., Orrego, R., y Matus, F. 2006. Caracterización y zonificación edáfica y climática de la Región de Coquimbo, Chile. Revista de la Ciencia del Suelo y Nutrición Vegetal 6(3):52-74.

Orrego, R., Abarca-del-Río, R., Ávila, A., and Morales, L. 2016. Enhanced mesoscale climate projections in TAR and AR5 IPCC scenarios: a case study in a Mediterranean climate (Araucanía Region, south central Chile). Springer Plus 5(1):1-23.

Pathak, T.B., Maskey, M.L., Dahlberg, J.A., Kearns, F., Bali, K.M., and Zaccaria, D. 2018. Climate change trends and impacts on California agriculture: a detailed review. Agronomy 8(3):25.

Poblete, A.G., Iranzo, D.A., and Aguiar, L.A. 2013. Análisis espacio-temporal del posible corrimiento de la posición latitudinal del Anticiclón Subtropical del Pacífico Sur (L). Revista Universitaria de Geografía 22(1):129-146.

Quintana, J.M., and Aceituno, P. 2012. Changes in the rainfall regime along the extratropical west coast of South America (Chile): $30-43^{\circ} \mathrm{S}$. Atmósfera 25(1):1-22.

Rahimi, J., Laux, P., and Khalili, A. 2020. Assessment of climate change over Iran: CMIP5 results and their presentation in terms of Köppen-Geiger climate zones. Theoretical and Applied Climatology 141(1):183-199.

Rohli, R.V., Joyner, T.A., Reynolds, S.J., and Ballinger, T.J. 2015. Overlap of global Köppen-Geiger climates, biomes, and soil orders. Physical Geography 36(2):158-175.

Rubel, F., and Kottek, M. 2010. Observed and projected climate shifts 1901-2100 depicted by world maps of the Köppen-Geiger climate classification. Meteorologische Zeitschrift 19(2):135-141.

Saavedra, M., Calvo, M., y Jiménez, C. 2011. Caracterización climática de la circulación atmosférica en América del Sur. Revista de Investigación de Física 14:111401761

Sarricolea Espinoza, P., Meseguer-Ruiz, Ó., y Marín-Vide, J. 2014. Variabilidad y tendencias climáticas en Chile central en el período 1950-2010 mediante la determinación de los tipos sinópticos de Jenkinson y Collison. Boletín de la Asociación de Geógrafos Españoles 64:227-247.

Sarricolea, P., Herrera-Ossandon, M., and Meseguer-Ruiz, Ó. 2017. Climatic regionalisation of continental Chile. Journal of Maps 13(2):66-73.

Vuille, M., Franquist, E., Garreaud, R., Lavado Casimiro, W.S., and Cáceres, B. 2015. Impact of the global warming hiatus on Andean temperature. Journal of Geophysical Research: Atmospheres 120(9):3745-3757.

Wang, S., Huang, G.H., Lin, Q.G., Li, Z., Zhang, H., and Fan, Y.R. 2014. Comparison of interpolation methods for estimating spatial distribution of Precipitation in Ontario, Canada. International Journal of Climatology 34(14):3745-3751.

Wu, D., Wang, P., Jiang, C., Yang, J., Huo, Z., and Yu, Q. 2019. Measured phenology response of unchanged crop varieties to long-term historical climate change. International Journal of Plant Production 13(1):47-58.

Zhang, C. 2013. Madden-Julian oscillation: Bridging weather and climate. Bulletin of the American Meteorological Society 94(12):1849-1870. 